https://helda.helsinki.fi

Coronary heart disease risk factor levels in eastern and western Finland from 1980 to 2011 in the cardiovascular risk in Young Finns study

\title{
Vähämurto, Lauri
}

2019-01

Vähämurto , L , Pahkala , K, Magnussen , C G , Hutri-Kähönen , N , Kähönen , M , Laitinen , T , Taittonen , L , Tossavainen , P , Lehtimäki , T , Jokinen , E, Telama , R, Rönnemaa , T , Viikari , J , Juonala , M \& Raitakari , O T 2019 , ' Coronary heart disease risk factor levels in eastern and western Finland from 1980 to 2011 in the cardiovascular risk in Young Finns study ' , Atherosclerosis , vol. 280 , pp. 92-98 . https://doi.org/10.1016/j.atherosclerosis.2018.11.007

http://hdl.handle.net/10138/312538

https://doi.org/10.1016/j.atherosclerosis.2018.11.007

publishedVersion

Downloaded from Helda, University of Helsinki institutional repository.

This is an electronic reprint of the original article.

This reprint may differ from the original in pagination and typographic detail.

Please cite the original version. 


\title{
Coronary heart disease risk factor levels in eastern and western Finland from 1980 to 2011 in the cardiovascular risk in Young Finns study
}

\author{
Lauri Vähämurto $^{\mathrm{a}, *}$, Katja Pahkala ${ }^{\mathrm{a}, \mathrm{b}}$, Costan G. Magnussen ${ }^{\mathrm{a}, \mathrm{c}}$, Nina Hutri-Kähönen ${ }^{\mathrm{d}}$, \\ Mika Kähönen ${ }^{\mathrm{e}}$, Tomi Laitinen ${ }^{\mathrm{f}}$, Leena Taittonen ${ }^{\mathrm{g}}$, Päivi Tossavainen ${ }^{\mathrm{h}}$, Terho Lehtimäki ${ }^{\mathrm{i}}$, \\ Eero Jokinen ${ }^{\mathrm{j}}$, Risto Telama ${ }^{\mathrm{k}}$, Tapani Rönnemaa ${ }^{1}$, Jorma Viikari ${ }^{1}$, Markus Juonala ${ }^{\mathrm{a}, \mathrm{l}}$, \\ Olli T. Raitakari ${ }^{\mathrm{a}, \mathrm{m}}$
}

${ }^{a}$ Research Center of Applied and Preventive Cardiovascular Medicine, University of Turku, Turku, Finland

${ }^{\mathrm{b}}$ Paavo Nurmi Centre, Sports and Exercise Medicine Unit, Department of Physical Activity and Health, University of Turku, Turku, Finland

${ }^{\mathrm{c}}$ Menzies Institute for Medical Research, University of Tasmania, Hobart, Australia

${ }^{\mathrm{d}}$ Department of Pediatrics, University of Tampere and Tampere University Hospital, Tampere, Finland

${ }^{\mathrm{e}}$ Faculty of Medicine and Life Sciences Department of Clinical Physiology, Tampere University Hospital and Faculty of Medicine and Life Sciences, University of Tampere,

Tampere, Finland

${ }^{\mathrm{f}}$ Department of Clinical Physiology and Nuclear Medicine, University of Eastern Finland and Kuopio University Hospital, Kuopio, Finland

${ }^{\mathrm{g}}$ Vaasa Central Hospital, Vaasa, Finland

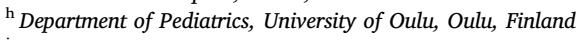

${ }^{i}$ Department of Clinical Chemistry, Fimlab Laboratories and Finnish Cardiovascular Research Center-Tampere, Faculty of Medicine and Life Sciences, University of

Tampere, Finland

${ }^{\mathrm{j}}$ Department of Pediatric Cardiology, Hospital for Children and Adolescents, University of Helsinki, Helsinki, Finland

${ }^{\mathrm{k}}$ LIKES-Research Center for Sport and Health Sciences, Jyväskylä, Finland

${ }^{1}$ Department of Medicine, University of Turku and Division of Medicine, Turku University Hospital, Turku, Finland

${ }^{\mathrm{m}}$ Department of Clinical Physiology and Nuclear Medicine, Turku University Hospital, Turku, Finland

\section{H I G H L I G H T S}

- Eastern Finns had higher blood pressure, total cholesterol and blood glucose from 1980 to 2011.

- Currently, the CHD risk factor profile is similar between participants with childhood residency in east or west.

- Results suggest that CHD mortality in the next decades might remain higher in eastern compared to western Finns.

\section{A R T I C L E I N F O}

\section{Keywords:}

Cardiovascular disease

Risk factors

Longitudinal

Population

Adulthood

Atherosclerosis precursors

\begin{abstract}
A B S T R A C T
Background and aims: In the 1960s and 1970s, Finland, mortality due to coronary heart disease (CHD) was over $30 \%$ higher among Finns residing in the east of the country compared with those residing in the west. Today, CHD mortality remains 20\% higher among eastern Finns. The higher incidence of CHD mortality among eastern Finns has largely been explained by higher risk factor levels. Using a unique longitudinal cohort, we aimed to determine if participants who resided in eastern Finland during childhood had higher CHD risk factors in adulthood and from childhood to adulthood.

Methods: The study population included 2063 participants of the Cardiovascular Risk in Young Finns Study, born during the period 1962-1977, with risk factor data available from baseline (1980) when participants were aged 3-18 years, and had risk factor data collected again in adulthood (2011) when aged 34-49 years. Results: Adult CHD risk factor profile was similar for those who resided in eastern or western Finland in childhood. Over life-course from 1980 to 2011, those subjects with childhood residency in eastern Finland had, on average, higher systolic $(p=0.006)$ and diastolic $(p=0.0009)$ blood pressures, total $(p=0.01)$ and LDLcholesterol $(p=0.01)$, triglycerides $(p=0.04)$, apoB $(p=0.02)$, and serum glucose $(p<0.0001)$ than those who resided in western Finland in childhood.

Conclusions: Our sample of adult Finns aged 34-49 years had a similar CHD risk factor profile irrespective of whether they resided in eastern or western Finland during their childhood. However, when considering
\end{abstract}

\footnotetext{
*Corresponding author. Research Center of Applied and Preventive Cardiovascular Medicine, Kiinamyllynkatu 10, 20520, Turku, Finland.

E-mail address: lauri.vahamurto@utu.fi (L. Vähämurto).
} 
participants risk factor profiles over a 31-year period, those who resided in eastern Finland in childhood were associated with a less favorable CHD risk factor profile than those who resided in western Finland in childhood. The observed differences suggest that future CHD mortality might remain higher in eastern Finland compared with western Finland.

\section{Introduction}

Coronary heart disease (CHD) is a major cause of death globally. In the 1960s, CHD mortality was found to be high in Finland compared to other countries [1], especially among men born in eastern Finland. The excess CHD risk observed amongst those residing or born in eastern Finland compared with western Finland was largely explained by a higher prevalence of risk factors: hypercholesterolemia, hypertension, and smoking. In response to the high rates of CHD in Finland and the observed east-west difference, a national program called the North Karelia project was launched in the 1970s aimed to modify lifestyle factors and improve risk factor levels to decrease CHD, particularly in eastern Finland [2]. From 1972 to 2012, age-adjusted CHD mortality in working-age men decreased by $82 \%$ and among working-age women by $84 \%$ in eastern Finland [3]. The major part of the decline in CHD mortality could be explained by the decrease in serum total cholesterol in men and the decrease in systolic blood pressure and serum total cholesterol in women [3]. CHD mortality also decreased in western Finland, but not as dramatically as observed in eastern Finland. Currently, eastern Finns still have approximately 20\% higher CHD mortality than western Finns (National Institute for Health and Welfare; 2012).

The Cardiovascular Risk in Young Finns Study is a nationwide ongoing study of Finnish children and adolescents that began in 1980 to examine atherosclerosis precursors [4]. One of the key purposes has been to study differences in cardiometabolic risk markers between eastern and western Finns. We have previously shown that participants who were resident in eastern Finland in childhood had, on average, higher total cholesterol in childhood [5], and higher blood pressure and total cholesterol as adults in 2001 [6] than those who resided in western Finland in childhood. By 2007, those currently living in eastern Finland had higher blood pressure than those who were currently living in western Finland [7].

Although regularly studied cross-sectionally, differences in CHD risk factors between eastern and western Finns in 2010s are not known. Also, the east-west differences in CHD risk factors have not been investigated in a longitudinal cohort over 31-years of follow-up from childhood to adulthood. Therefore, our aim was to investigate current east-west differences in CHD risk factors and to assess the role of eastwest residency in childhood. We hypothesized that risk factor differences between those resident in eastern or western Finland at baseline would be marginal in adulthood but those with baseline eastern Finland residency would have higher risk factor levels from childhood to adulthood.

\section{Materials and methods}

\subsection{Participants}

The Cardiovascular Risk in Young Finns Study is a population-based follow-up study on cardiovascular risk factors in Finland [4]. In 1980, children and adolescents aged 3-18 years were randomly chosen from the population register to form a representative sample of Finnish children. 3596 children participated in the first cross-sectional study carried out in five Finnish university cities with medical schools (Helsinki, Kuopio, Oulu, Tampere and Turku) and their rural surroundings. Since 1980, regular follow-ups have been performed. We used the data from follow-up studies with extensive data on anthropometry, blood pressure measurements and biochemical analyses (1980, 1983, 1986, 2001, 2007, 2011) (Fig. 1). 2063 participants attended the 2011 followup clinical examination. The study has been approved by the Joint Commission on Ethics of the Turku University and the Turku University Central Hospital and informed consent was obtained from all participants or their parents.

In this study, participants were grouped according to their baseline (1980) residency. The areas of Kuopio and Oulu were considered eastern, Helsinki, Tampere and Turku as western [8]. Geographically more accurate terms would be southwestern and northeastern but due to historical reasons and simplicity, we have used the terms eastern and western.

\subsection{Anthropometry, blood pressure, biochemical analyses}

Weight, height and waist circumference were measured and body mass index (BMI) calculated as weight $(\mathrm{kg}) /\left(\right.$ height $\left.{ }^{2}\left(\mathrm{~m}^{2}\right)\right)$. Blood pressure was measured with participants seated after a 5-min rest using a standard mercury sphygmomanometer in 1980 and 1983 and using a random zero sphygmomanometer at subsequent follow-ups. The average of three measurements was used. For those aged 3-years in 1980 , only systolic blood pressure was measured using an ultrasound

\begin{tabular}{|c|c|c|}
\hline $\mathrm{N}$ & Year & Age cohorts \\
\hline 3,596 & 1980 & $\begin{array}{llllll}3 & 6 & 12 & 15 & 18\end{array}$ \\
\hline 2,991 & 1983 & 6912151821 \\
\hline 2,779 & 1986 & 91215182124 \\
\hline $2737 *$ & 1989 & $\begin{array}{llllll}12 & 15 & 18 & 21 & 24 & 27\end{array}$ \\
\hline 2730* & 1992 & $\begin{array}{llllll}15 & 18 & 21 & 24 & 27 & 30\end{array}$ \\
\hline 2,283 & 2001 & $\begin{array}{llllll}24 & 27 & 30 & 33 & 36 & 39\end{array}$ \\
\hline 2,204 & 2007 & 303336394245 \\
\hline 2,063 & $2011 / 12$ & $34374043 \quad 4649$ \\
\hline
\end{tabular}

Fig. 1. Study design of the Cardiovascular Risk in Young Finns Study (follow-ups with extensive data on anthropometry, blood pressure measurements and biochemical analyses). 
device (Arteriosonde, Roche). Venous blood samples were drawn after an overnight fast in childhood and adulthood and measured and analyzed with standard enzymatic methods [4]. Computationally estimated values were used in 1980-86 for apolipoproteins A1 and B [9] and immunoturbidimetrically measured values after 1986 .

\subsection{Lifestyle risk factors and socioeconomic status}

Cigarette smoking, alcohol consumption, physical activity and socioeconomic status (SES) were determined from self-report questionnaires. Those smoking daily were classified as smokers. Alcohol consumption was measured as standard doses per week. Number of school years completed was used as a measure of participant SES in adulthood. Parental SES was estimated by two measures: school years of the more-educated parent $(1=$ less than 9 years, $2=9-12$ years, $3=$ over 12 years); and parental income ( $1=$ the lowest quartile, $2=$ the second and the third quartiles, $3=$ the highest quartile).

\subsection{Definition of hypertension, metabolic syndrome, type 2 diabetes and} fatty liver

Hypertension was classified as systolic blood pressure $\geq 140 \mathrm{mmHg}$ or diastolic blood pressure $\geq 90 \mathrm{mmHg}$ or the use of anti-hypertensive medication. The metabolic syndrome was defined according to the Harmonized criteria [10]. The definition included the following criteria: waist circumference $\geq 102 \mathrm{~cm}$ in men and $\geq 88 \mathrm{~cm}$ in women, fasting serum glucose $\geq 5.6 \mathrm{mmol} / 1$ or treatment, hypertriglyceridemia $\geq 1.7 \mathrm{mmol} / \mathrm{l}$, HDL-cholesterol $\leq 1.0 \mathrm{mmol} / 1$ in men and $\leq 1.3 \mathrm{mmol} / 1$ in women, and hypertension as systolic blood pressure $\geq 130 \mathrm{mmHg}$ or diastolic blood pressure $\geq 85 \mathrm{mmHg}$ or the use of anti-hypertensive medication. A diagnosis required that any three of the five criteria be present. Pregnant women in $2007(n=37)$ and/or in $2011(n=13)$ were excluded from analyses involving the metabolic syndrome in adulthood. Participants were diagnosed as having type 2 diabetes if they had serum fasting glucose $\geq 7 \mathrm{mmol} / 1$ or GHbA1c $\geq 6.5 \%$ or selfreported diabetes or use of medication [11]. Hepatic steatosis was evaluated in 2040 participants using a validated protocol [12] and Sequoia 512 ultrasound mainframes (Acuson, Mountain View, CA, USA) with $4.0 \mathrm{MHz}$ adult abdominal transducers. Hepatic steatosis was determined according to liver-to-kidney contrast, parenchymal brightness, deep beam attenuation, and bright vessel walls. The presence of hepatic steatosis was assessed visually by a trained ultrasonographer who was not-blinded to participant details. Participants were classified into fatty liver and normal liver groups [13].

\subsection{Statistical analyses}

CHD risk factors in 2011 for participants are displayed stratified by sex and baseline residency (eastern or western). Continuous variables are presented as means (standard deviation, SD) for normally distributed variables or medians (interquartile range) for variables with a skewed distribution. Categorical variables are presented as proportions. P-values for CHD risk factors in 2011 were analyzed using t-tests. Nonnormally distributed risk factors were first log-transformed. Categorical risk factors were analyzed using the chi-square test.

For longitudinal analyses, CHD risk factors Z-scores were generated for each follow-up year from 1980 to 2011. Non-normally distributed risk factors (BMI, triglycerides, insulin, glucose) were first log-transformed. The longitudinal differences between participants with eastern/western baseline residency were analyzed with repeated measures linear mixed models. Models were adjusted for age and sex and the year of study using an unstructured covariance structure. As there were no sex *east-west baseline residency interactions, data for males and females were analyzed together. We further analyzed the

Table 1

Coronary heart disease risk factors in 2011 (mean \pm SD or median [interquartile range]*) according to the place of residence at baseline in 1980 .

\begin{tabular}{|c|c|c|c|c|c|c|c|c|c|}
\hline \multirow[b]{4}{*}{$\mathrm{N}$ range } & \multicolumn{4}{|c|}{ Males $(n=934)$} & \multicolumn{5}{|c|}{ Females $(\mathrm{n}=1128)$} \\
\hline & \multicolumn{2}{|c|}{ Eastern 1980} & \multicolumn{2}{|c|}{ Western 1980} & \multicolumn{2}{|c|}{ Eastern 1980} & \multicolumn{2}{|c|}{ Western 1980} & \multirow[t]{2}{*}{$p^{\mathrm{a}}$} \\
\hline & Mean & SD & Mean & SD & Mean & SD & Mean & SD & \\
\hline & \multicolumn{2}{|c|}{$362-434$} & \multicolumn{2}{|c|}{$424-496$} & \multicolumn{2}{|c|}{$449-527$} & \multicolumn{2}{|c|}{$517-588$} & \\
\hline Age (years) & 41.8 & 5.0 & 41.8 & 5.1 & 42.2 & 4.9 & 41.7 & 5.0 & 0.94 \\
\hline Height $(\mathrm{cm})$ & 179 & 7 & 180 & 7 & 165 & 6 & 167 & 6 & 0.0005 \\
\hline Birth weight (g) & 3570 & 600 & 3600 & 550 & 3460 & 520 & 3480 & 520 & 0.39 \\
\hline BMI $\left(\mathrm{kg} / \mathrm{m}^{2}\right)^{*}$ & 26.3 & 5.1 & 26.3 & 5.4 & 25.2 & 6.7 & 24.9 & 6.6 & 0.76 \\
\hline Waist $(\mathrm{cm})$ & 96.2 & 12.2 & 97.6 & 13.2 & 87.4 & 14.6 & 87.9 & 13.5 & 0.13 \\
\hline Systolic blood pressure (mmHg) & 123 & 13 & 123 & 14 & 115 & 13 & 116 & 15 & 0.61 \\
\hline Diastolic blood pressure $(\mathrm{mmHg})$ & 78 & 10 & 77 & 11 & 72 & 9 & 72 & 10 & 0.73 \\
\hline Hypertension (\%) & \multicolumn{2}{|l|}{24.7} & \multicolumn{2}{|l|}{24.1} & \multicolumn{2}{|l|}{15.9} & \multicolumn{2}{|l|}{14.6} & 0.58 \\
\hline Total cholesterol (mmol/L) & 5.31 & 0.99 & 5.33 & 1.03 & 5.11 & 0.89 & 5.04 & 0.88 & 0.47 \\
\hline HDL-cholesterol (mmol/L) & 1.19 & 0.28 & 1.21 & 0.31 & 1.43 & 0.32 & 1.43 & 0.33 & 0.71 \\
\hline LDL-cholesterol (mmol/L) & 3.45 & 0.91 & 3.42 & 0.89 & 3.17 & 0.74 & 3.12 & 0.76 & 0.29 \\
\hline ApoA1 (g/L) & 1.52 & 0.21 & 1.52 & 0.22 & 1.66 & 0.24 & 1.64 & 0.24 & 0.27 \\
\hline ApoB $(g / L)$ & 1.15 & 0.29 & 1.16 & 0.30 & 0.99 & 0.25 & 0.97 & 0.26 & 0.62 \\
\hline Triglycerides $(\mathrm{mmol} / \mathrm{L}) *$ & 1.26 & 0.92 & 1.26 & 1.12 & 0.95 & 0.51 & 0.95 & 0.51 & 0.87 \\
\hline Insulin $(\mathrm{mU} / \mathrm{L})^{*}$ & 8.04 & 7.05 & 7.57 & 7.83 & 6.94 & 6.57 & 6.79 & 6.89 & 0.91 \\
\hline Glucose (mmol/L)* & 5.47 & 0.63 & 5.47 & 0.63 & 5.15 & 0.64 & 5.15 & 0.64 & 0.31 \\
\hline Metabolic syndrome (\%) & \multicolumn{2}{|l|}{24.1} & \multicolumn{2}{|l|}{27.4} & \multicolumn{2}{|l|}{17.5} & \multicolumn{2}{|l|}{17.7} & 0.36 \\
\hline Type 2 diabetes (\%) & \multicolumn{2}{|l|}{3.7} & \multicolumn{2}{|l|}{4.4} & \multicolumn{2}{|l|}{3.8} & \multicolumn{2}{|l|}{3.8} & 0.73 \\
\hline Fatty liver (\%) & \multicolumn{2}{|l|}{27.4} & \multicolumn{2}{|l|}{29.5} & \multicolumn{2}{|l|}{12.5} & \multicolumn{2}{|l|}{9.3} & 0.69 \\
\hline Smokers $(\%)$ & \multicolumn{2}{|l|}{19.4} & \multicolumn{2}{|l|}{15.3} & 13.4 & & 12.5 & & 0.16 \\
\hline Physical activity index (range 5-15) & 8.95 & 1.83 & 8.80 & 1.91 & 9.10 & 1.78 & 9.16 & 1.91 & 0.65 \\
\hline SES (school years) & 14.9 & 3.6 & 14.8 & 4.0 & 15.7 & 3.2 & 15.7 & 3.5 & 0.74 \\
\hline Parental SES/school years (range 1-3) & 1.87 & 0.80 & 1.94 & 0.78 & 1.78 & 0.76 & 1.92 & 0.78 & 0.006 \\
\hline Parental SES/income (range 1-3) & 1.90 & 0.72 & 2.03 & 0.67 & 1.90 & 0.73 & 2.02 & 0.68 & $<0.0001$ \\
\hline Alcohol consumption (doses per week) & 4 & 9 & 6 & 10 & 2 & 5 & 2 & 5 & 0.20 \\
\hline
\end{tabular}

SES: socioeconomic status. Parental SES: higher value refers to more school years/higher income.

${ }^{a}$ p-values for east-west difference in analyses where sexes are combined. 
longitudinal differences in CHD risk factors with adjustment for parental SES (school years and income status) at baseline as it was different between participants with eastern or western baseline residency and is known to associate with traditional CHD risk factors. The analyses were performed with SAS version 9.3 (SAS institute, Inc, Cary, NC). A twotailed $p$-value of $<0.05$ was considered statistically significant.

\section{Results}

3.1. Coronary heart disease risk factors in 2011 according to baseline residency

Males and females were divided equally among the east-west groups $(p=0.71)$ and the mean age between the groups was similar (Table 1). Those resident in eastern Finland at baseline were, on average, shorter than those who were resident in western Finland at baseline. Irrespective of baseline residency, there were no differences in CHD risk factors in 2011 between participants. The prevalence of type 2 diabetes,
A

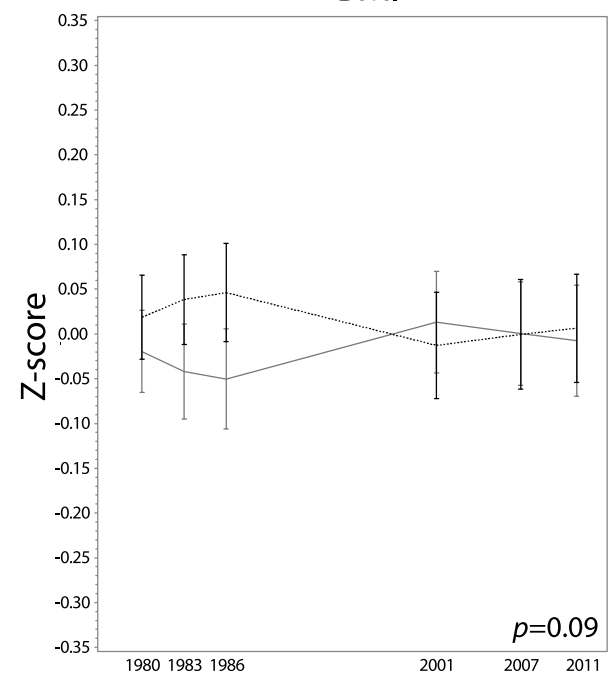

BMI

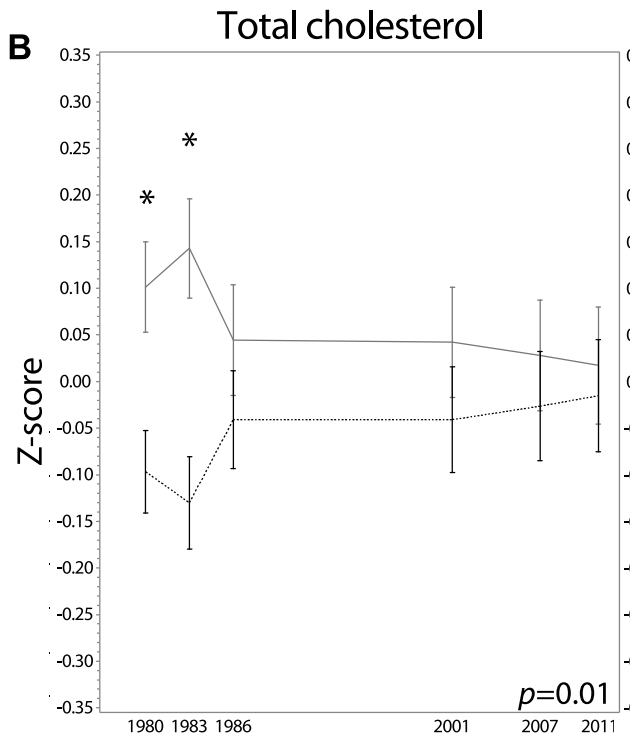

Systolic blood pressure

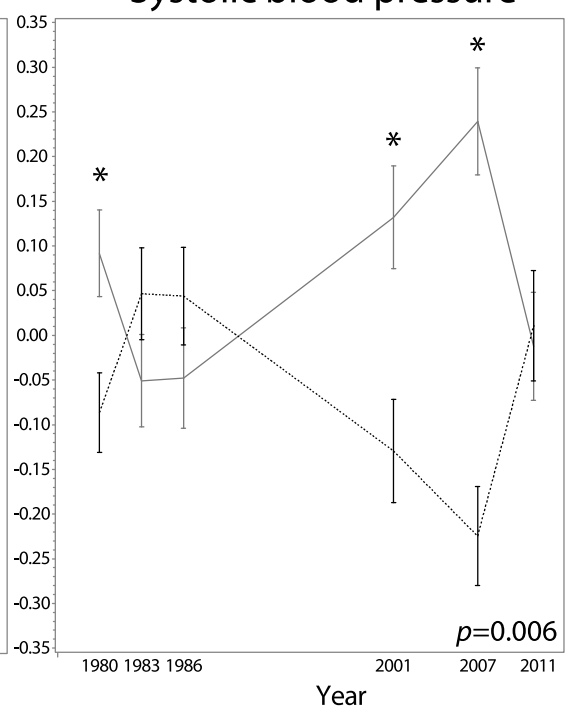

LDL- cholesterol

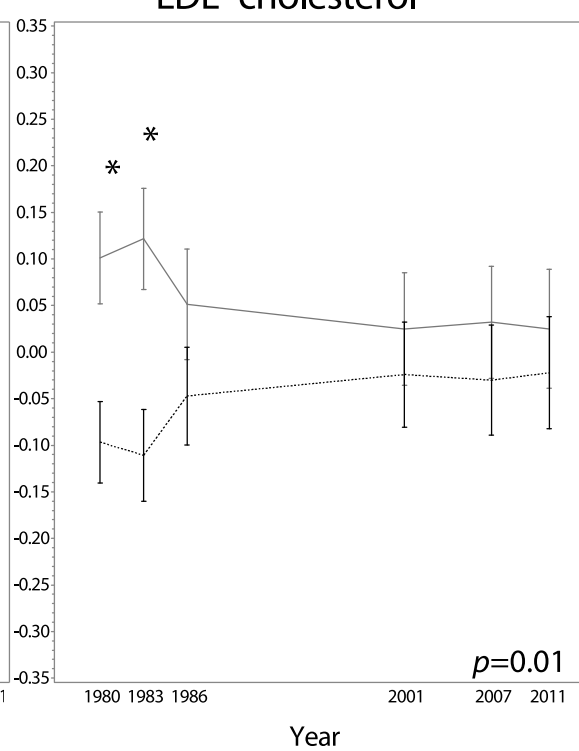

Diastolic blood pressure

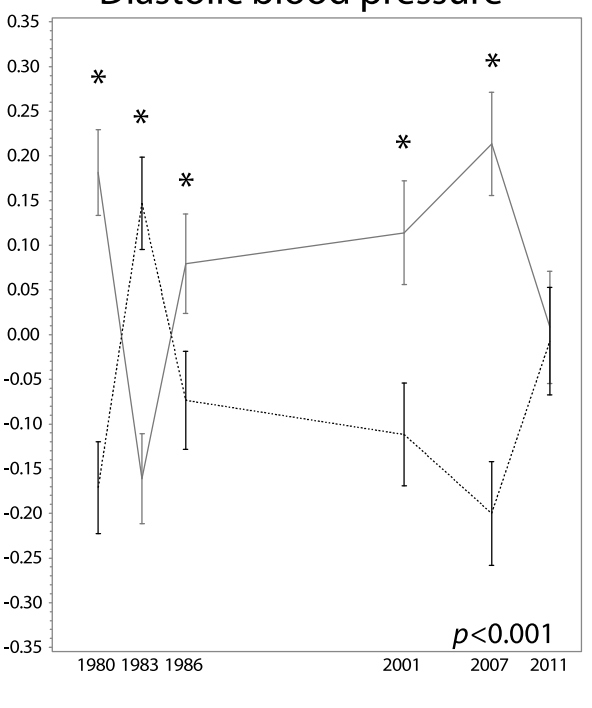

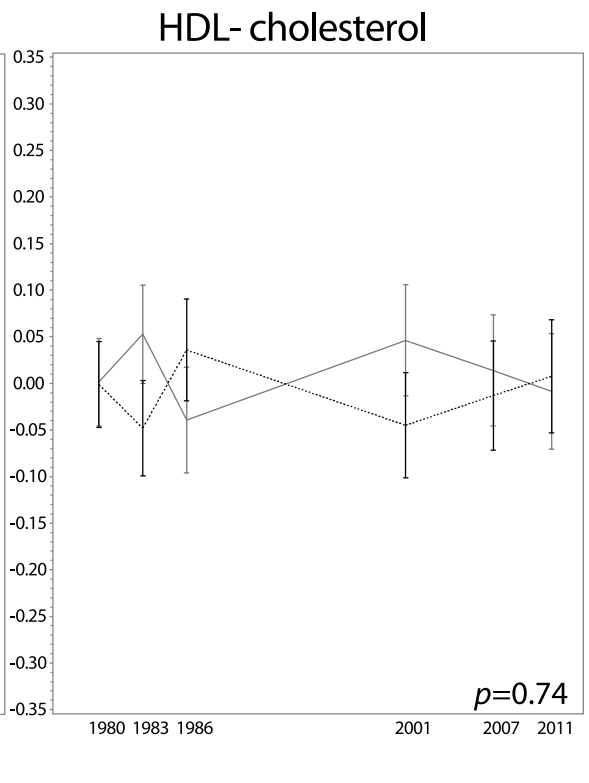

Fig. 2. Longitudinal analyses of coronary heart disease risk factors from 1980 to 2011 .

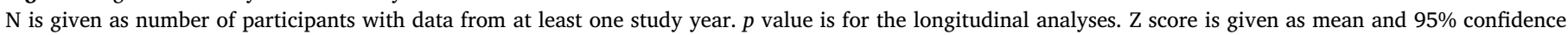

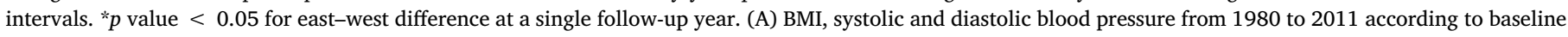

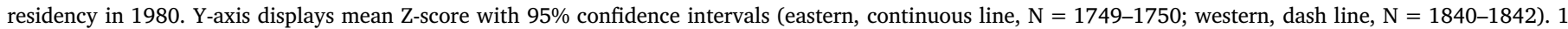

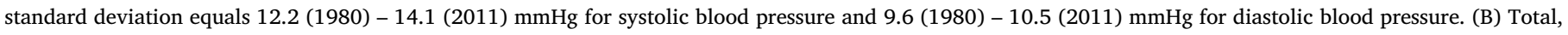

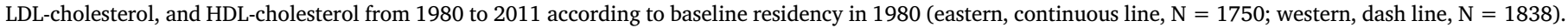

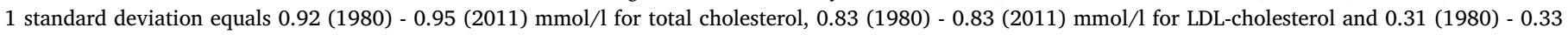

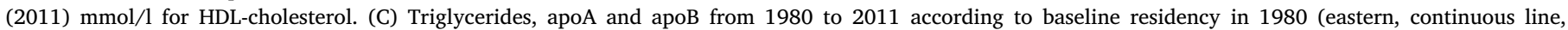

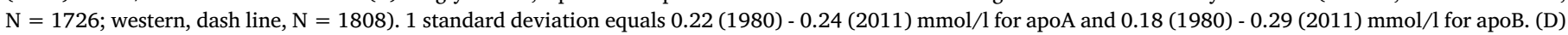

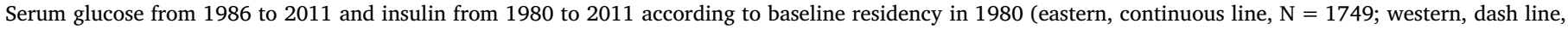
$\mathrm{N}=1838$ ). 
L. Vähämurto et al.

Atherosclerosis 280 (2019) 92-98

hypertension, and fatty liver were also similar between those resident in eastern and western Finland at baseline. Parental SES, as indicated by parent school years completed and family income at baseline, was higher in those resident in western compared with eastern Finland.

We further analyzed the prevalence of hepatic steatosis among males and females and in association with alcohol consumption (data not shown). Prevalence among all men was higher than among women (28.5\% vs. $10.8 \%, p<0.0001)$. Prevalence of hepatic steatosis was higher in men than in women also among those who consumed less than 10 standard doses of alcohol per week ( $26.3 \% v s .9 .8 \%, p=0.02)$. Those who consumed 10 or more standard doses of alcohol per week (263 men, 96 women) had higher prevalence of hepatic steatosis than those who consumed less than 10 standard doses per week (657 men and 1007 women) both among men $(33.8 \% v s .26 .3 \%, p=0.02)$ and women $(20.8 \%$ vs. $9.8 \%, p=0.002)$.
C

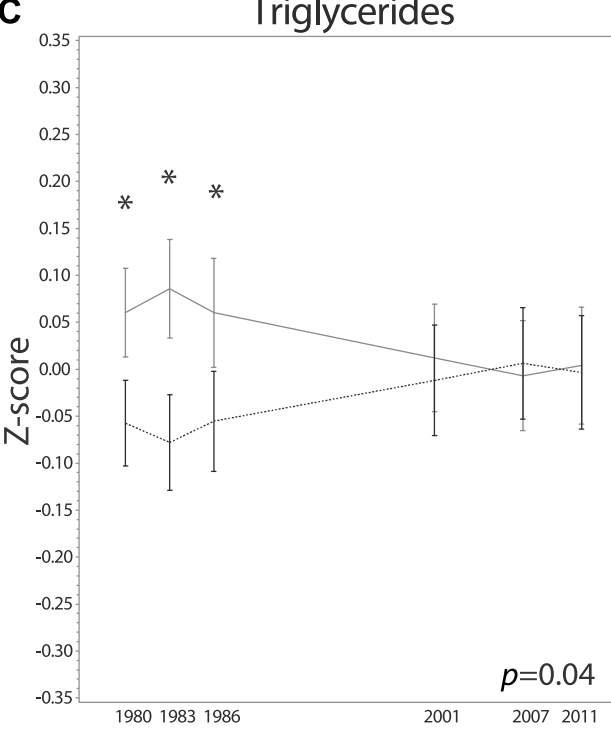

3.2. Coronary heart disease risk factors from 1980 to 2011 according to baseline residency

3.2.1. Anthropometric measurements

From 1980 to 2011, BMI was not statistically different between those resident in eastern or western Finland at baseline. Those with eastern baseline residency had significantly higher, on average, systolic and diastolic blood pressures from 1980 to 2011 compared with those residing in western Finland at baseline. As indicated by the $95 \%$ confidence intervals, eastern participants had higher systolic blood pressure in 1980, 2001, and 2007 and higher diastolic blood pressure in 1980, 1986, 2001 and 2007 compared with western residents. Eastwest difference in blood pressure was largest in 2007 but was not apparent in 2011 (Fig. 2A).

3.2.2. Lipids and apolipoproteins

On average, those residing in eastern Finland at baseline had higher total and LDL-cholesterol (Fig. 2B), triglycerides and apo (Fig. 2C) compared with western participants during the 31 years of follow-up. As indicated by the $95 \%$ confidence intervals, concentrations were
D

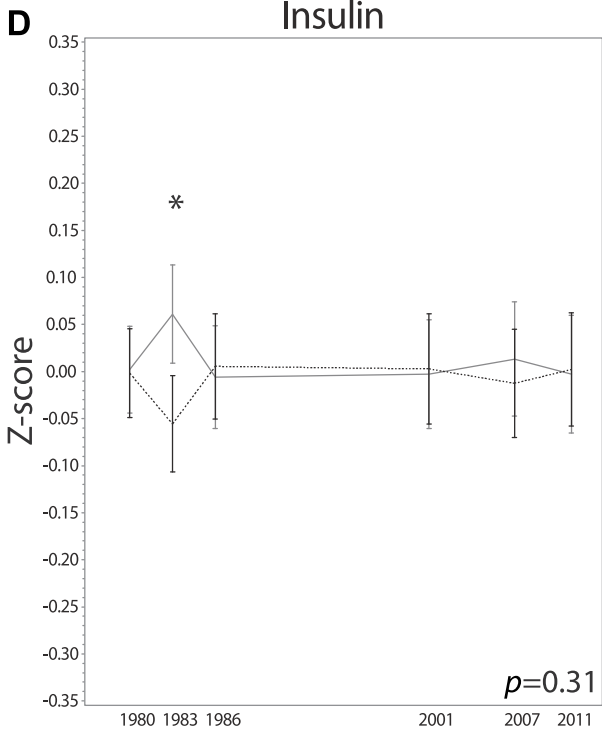

Apo A

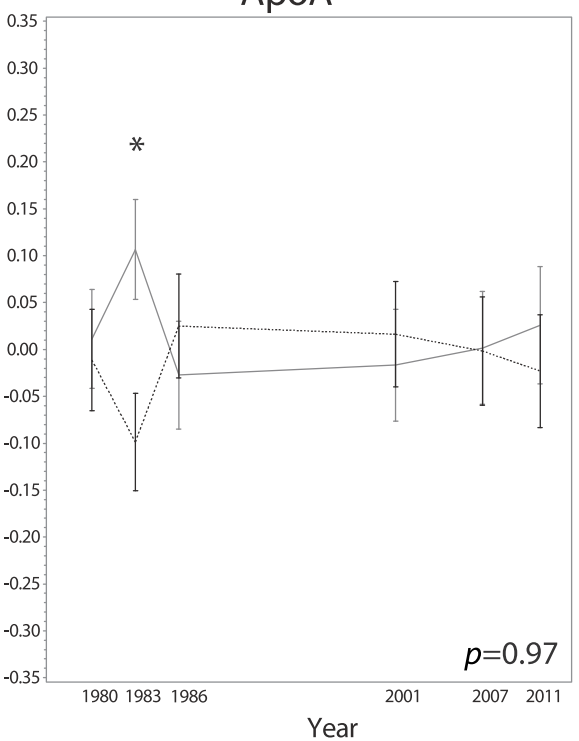

Apo

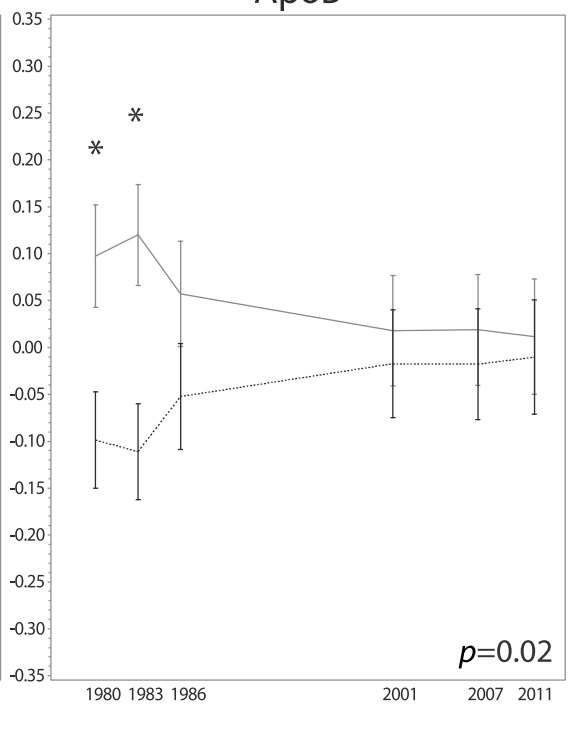

Glucose

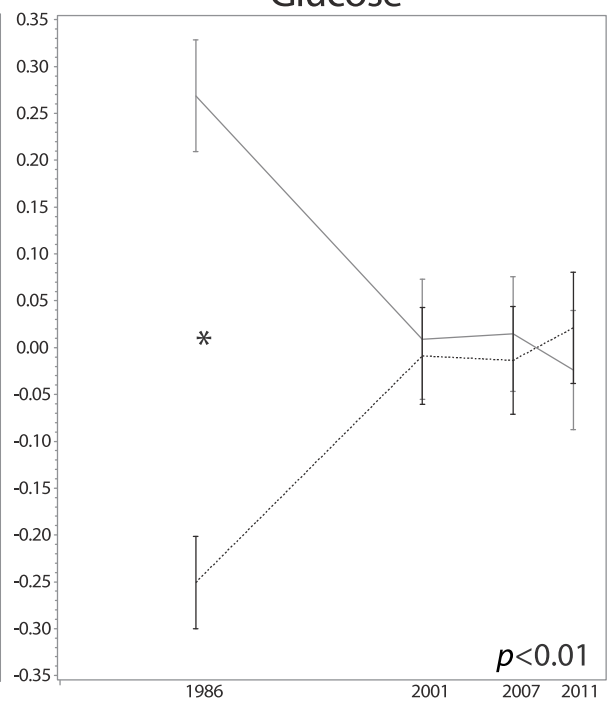

Year

Fig. 2. (continued)

96 
higher among eastern participants in 1980, 1983, and 1986 for triglycerides, after which the differences were no longer significant. From 1980 to 2011, we observed no east-west difference, on average, for HDL-cholesterol and apoA. At single follow-up years, we only observed a difference for apoA in 1983.

\subsubsection{Glucose metabolism}

Participants with baseline residency in eastern Finland had higher serum glucose on average compared with those with western baseline residency in the longitudinal analyses. As indicated by the $95 \%$ confidence intervals, serum glucose was higher among eastern participants in 1986 but was similar between eastern and western groups in 2001, 2007 , and 2011. In the longitudinal analyses there was no east-west difference in serum insulin. As indicated by the $95 \%$ confidence intervals, serum insulin was similar between eastern and western participants from 1980 to 2011 except that eastern residents had higher values in 1983 (Fig. 2D).

We further analyzed the longitudinal differences in CHD risk factors with adjustment for baseline parental SES (school years and income class) in addition to adjustment for age and sex. Except for triglycerides, the observed east-west differences in risk factors remained statistically significant.

\section{Discussion}

Compared with those who resided in western Finland in childhood, residing in eastern Finland in childhood was associated with higher average blood pressure, total and LDL-cholesterol, triglycerides, apoB, and serum glucose from 1980 to 2011. In 2011, there were no differences in traditional CHD risk factors between eastern or western residents.

We found no evidence for significant differences in hepatic steatosis between eastern and western Finns. Instead we found higher prevalence of hepatic steatosis in men compared with women, also among those used low amounts of alcohol. In our previous study, risk of fatty liver was higher among males, those of older age, and those with elevated levels of waist circumference, alanine aminotransferase, BMI, triglycerides, systolic blood pressure, insulin, higher alcohol consumption and/or lower physical activity [13].

The heightened CHD mortality among eastern Finns in the 1960s was accompanied by a higher prevalence of hypertension, smoking and hypercholesterolemia compared with individuals from other nations and those from western Finland [1]. In the nationwide FINRISK-study in 1982, total cholesterol levels among men and systolic blood pressure levels in both men and women in eastern Finland remained comparatively higher on average than among their counterparts from western Finland, but ten years later these east-west differences had disappeared [14]. In our prior study, eastern residents had, on average, higher total cholesterol levels at baseline (1980) [15] and in 2001 had higher total cholesterol and blood pressure levels [6] than western residents at baseline. In 2007, those currently living in eastern Finland had higher blood pressure on average than those living in the west [7]. Our longitudinal findings reported here indicate that despite similar CHD risk factor levels currently existing between eastern and western Finns, there remains a residual burden or legacy effect of higher CHD risk factors from past decades in the east, as the earlier also suggested $[3,16]$. Carotid intima-media thickness, associated with future CV events [17], has also been found higher in eastern Finns compared with western Finns in other studies [16] and in our study [7].

The narrowing of east-west differences in CHD risk factors has occurred in conjunction with an overall decline in CHD risk factor levels and CHD mortality in Finland. CHD mortality in Finland fell by over $80 \%$ among working-age men and women from 1972 to 2012 [3]. In impact analyses of the FINRISK-cohort, the diminishing CHD risk factor levels in the population accounted for over 95\% of the reduction in CHD mortality in the 1970s [18] and two thirds of the CHD mortality reduction from 2002 to 2012. The remaining last third of the decline in CHD mortality in the latest decade was due to changes in other primary risk factors such as diet and physical activity, and secondary prevention with medication and the treatment of acute cardiac events [3]. In the latest FINRISK-study, the CHD mortality in 35-74 year-old Finns was $17 \%$ lower in western men and $15 \%$ lower among western women than in eastern Finland [3]. According to the National Institute for Health and Welfare's data, eastern Finns continued to have 20\% higher CHD mortality than Western Finns in 2012. The WOSCOPS- study found that treatment with pravastatin for 5-years reduced cardiovascular mortality and hospitalizations over a 20-year period, even after the discontinuation of the drug [19]. The higher CHD mortality still found in eastern Finns compared with western Finns supports the legacy effect of an earlier, higher risk CHD profile.

In this study, we chose to study east-west differences in CHD risk factors according to baseline residency. Migration from eastern to western Finland has been notable. For example, we have previously found that Young Finns participants who migrated from east-to-west between 1980 and 2007 had lower CHD risk factors and carotid intimamedia thickness compared with those who remained in the east [7]. Therefore, the contemporary and long-term east-west differences might be more pronounced than we have shown in the present study.

Participants who resided in the east at baseline had lower parental socioeconomic status at baseline and were shorter after 31 years of follow-up than those who resided in the west at baseline. Lower socioeconomic status has been found to associate with poorer CHD risk profile [20]. Short stature may associate with lower socioeconomic status [21] but overall, the association of height with CHD risk remains unclear [22,23].

Earlier studies have suggested that genetic differences within Finland could contribute to the observed east-west difference in CHD risk factor levels [5]. Researchers have concluded that Finland was settled from two directions [24] and genetic differences between eastern and western Finns are larger than between some nations in Europe. Some studies have suggested [25] that being born in East Finland is a more important CHD risk factor than is living there, which might be due to genetics, epigenetics or inherited health behaviors.

Another cohort of the Finnish population, the national FINRISK/ FINDIET-study has studied diet regularly since 1982 [26]. In their study, saturated fat intake as energy percent decreased from $20 \%$ in 1982 to $12 \%$ in 2007 and increased to $14 \%$ in 2012 . The effect of dietary changes counted for $0.3-0.5 \mathrm{mmol} / 1$ change in serum total cholesterol in the FINRISK-study between 1982 and 2012. Analyses for effect of dietary changes on total cholesterol differences specifically between eastern and western Finns have nevertheless not been reported. The FINDIET-study [27] also found that salt intake among Finnish population reduced from $13 \mathrm{~g}$ /day to $8-9 \mathrm{~g} /$ day in men and $11 \mathrm{~g} /$ day to $7 \mathrm{~g} / \mathrm{d}$ in women between 1979 and 2007. As the Young Finns Study participants are representative of the Finnish population we suspect that their dietary choices and nutritional intakes are in accordance with the FINRISK/FINDIET-studies.

This study has some limitations. The loss to follow-up is inevitable in longitudinal studies. However, we have found that risk factor levels are essentially similar among participants and non-participants at baseline [4]. Because of our young study population we cannot yet study the east-west differences in CHD and other clinical end-points. Further, we are unable to provide systematically similar data on a given nutrient, food item or e.g. salt intake throughout the study years as the methods used to assess diet have changed during the 30 years of followup. Also the questionnaires assessing physical activity habits have been modified during the follow-up to capture as well as possible the behaviour in the given age group. A further limitation is that questionnaires were used to assess data on lifestyles and e.g. consumption of alcohol. The prospective study design, follow-up time extending 30 years and detailed phenotyping of Young Finns participants are the main strengths of this study. 
In conclusion, we found that CHD risk profile in 2011 was similar irrespective of participant's eastern or western residency in childhood. However, in longitudinal analyses from 1980 to 2011, participants who were resident in eastern Finland at baseline had a higher CHD risk profile, on average, compared with those resident in western Finland at baseline. These findings suggest that we might see a higher prevalence of clinical end-points in eastern Finns than in western Finns in the future owing to a legacy effect of higher CHD risk profile in childhood. However, the similar risk factor profile observed today, suggests the excess CHD mortality observed amongst eastern Finns might diminish in the future.

\section{Conflicts of interest}

The authors declared they do not have anything to disclose regarding conflict of interest with respect to this manuscript.

\section{Financial support}

The Young Finns Study has been financially supported by the Academy of Finland: grants 286284, 134309 (Eye), 126925, 121584, 124282, 129378 (Salve), 117787 (Gendi), and 41071 (Skidi); the Social Insurance Institution of Finland; Competitive State Research Financing of the Expert Responsibility area of Kuopio, Tampere and Turku University Hospitals (grant X51001); Juho Vainio Foundation; Paavo Nurmi Foundation; Finnish Foundation for Cardiovascular Research; Finnish Cultural Foundation; Tampere Tuberculosis Foundation; Emil Aaltonen Foundation; Yrjö Jahnsson Foundation; Signe and Ane Gyllenberg Foundation; and Diabetes Research Foundation of Finnish Diabetes Association. CGM is supported by a National Heart Foundation of Australia Future Leader Fellowship (100849).

\section{Acknowledgements}

We acknowledge the expert technical assistance in data management and statistical analyses provided by Noora Kartiosuo and Johanna Ikonen.

\section{References}

[1] A. Keys, C. Aravanis, H.W. Blackburn, F.S. Van Buchem, R. Buzina, B.D. Djordjević, et al., Epidemiological studies related to coronary heart disease: characteristics of men aged 40-59 in seven countries, Acta medica Scand 460 (1966) 1-392.

[2] P. Puska, K. Koskela, H. Pakarinen, P. Puumalainen, V. Soininen, J. Tuomilehto, The North Karelia Project: a programme for community control of cardiovascular diseases, Scand. J. Soc. Med. 4 (2) (1976) 57-60.

[3] P. Jousilahti, T. Laatikainen, V. Salomaa, A. Pietilä, E. Vartiainen, P. Puska, 40-Year CHD mortality trends and the role of risk factors in mortality decline: the North Karelia project experience, Glob Heart [Internet] 11 (2) (2016) 207-212. Available from: https://doi.org/10.1016/j.gheart.2016.04.004.

[4] O.T. Raitakari, M. Juonala, T. Rönnemaa, L. Keltikangas-Järvinen, L. Räsänen, M. Pietikäinen, et al., Cohort profile: the cardiovascular risk in young Finns study, Int. J. Epidemiol. 37 (6) (2008) 1220-1226.

[5] E. Pesonen, J. Viikari, H.K. Åkerblom, L. Räsänen, K. Louhivuori, S. Sarna, Geographic origin of the family as a determinant of serum levels of lipids in Finnish children, Circulation 73 (6) (1986) 1119-1126.

[6] M. Juonala, J.S. Viikari, N. Hutri-Kähönen, M. Pietikäinen, E. Jokinen, L. Taittonen, et al., The 21-year follow-up of the Cardiovascular Risk in Young Finns Study: risk factor levels, secular trends and east-west difference, J. Intern. Med. 255 (4) (2004) 457-468.

[7] L. Vähämurto, K. Pahkala, C.G. Magnussen, V. Mikkilä, N. Hutri-Kähönen, M. Kähönen, et al., east-west differences and migration in Finland: association with cardiometabolic risk markers and IMT. The cardiovascular risk in young Finns study, Scand J Public Health 44 (4) (2016 Jun) 402-410. Available from: http://sjp. sagepub.com/cgi/doi/10.1177/1403494815622859.

[8] M. Juonala, J.S. Viikari, M. Kähönen, L. Taittonen, T. Rönnemaa, T. Laitinen, et al., Geographic origin as a determinant of carotid artery intima-media thickness and brachial artery flow-mediated dilation: the Cardiovascular Risk in Young Finns study, Arterioscler. Thromb. Vasc. Biol. 25 (2) (2005) 392-398.

[9] O.T. Raitakari, V.P. Mäkinen, M.J. McQueen, J. Niemi, M. Juonala, M. Jauhiainen, et al., Computationally estimated apolipoproteins B and A1 in predicting cardiovascular risk, Atherosclerosis [Internet] 226 (1) (2013) 245-251. Available from: https://doi.org/10.1016/j.atherosclerosis.2012.10.049.

[10] K.G. Alberti, R.H. Eckel, S.M. Grundy, P.Z. Zimmet, J.I. Cleeman, K.A. Donato, et al., Harmonizing the metabolic syndrome: a joint interim statement of the International Diabetes Federation Task Force on Epidemiology and Prevention; National Heart, Lung, and Blood Institute; American Heart Association; World Heart Federation; International Atherosclerosis Society; and International Association for the Study of Obesity, Circulation 120 (16) (2009) 1640-1645.

[11] J. Nuotio, M. Oikonen, C.G. Magnussen, E. Jokinen, T. Laitinen, N. Hutri-Kähönen, et al., Cardiovascular risk factors in 2011 and secular trends since 2007: the cardiovascular risk in young Finns study, Scand. J. Publ. Health 42 (7) (2014) 563-571.

[12] M.A. Edens, P.M. van Ooijen, W.J. Post, M.J. Haagmans, W. Kristanto, P.E. Sijens, et al., Ultrasonography to quantify hepatic fat content: validation by $1 \mathrm{H}$ magnetic resonance spectroscopy, Obesity (Silver Spring) 17 (12) (2009) 2239-2244.

[13] E. Suomela, M. Oikonen, J. Virtanen, R. Parkkola, E. Jokinen, T. Laitinen, et al., Prevalence and determinants of fatty liver in normal-weight and overweight young adults. The Cardiovascular Risk in Young Finns Study, Ann. Med. 47 (1) (2015) 40-46.

[14] E. Vartiainen, P. Puska, P. Jousilahti, H.J. Korhonen, J. Tuomilehto, A. Nissinen, Twenty-year trends in coronary risk factors in north Karelia and in other areas of Finland, Int. J. Epidemiol. 23 (3) (1994) 495-504.

[15] J. Viikari, H.K. Åkerblom, T. Nikkari, A. Seppänen, M. Uhari, E. Pesonen, et al., Atherosclerosis precursors in Finnish children and adolescents. IV. Serum lipids in newborns, children and adolescents, Acta Paediatr. Scand. Suppl. 318 (1985) 103-109.

[16] L. Jartti, O.T. Raitakari, J. Kaprio, M.J. Järvisalo, J.O. Toikka, J. Marniemi, et al., Increased carotid intima-media thickness in men born in east Finland: a twin study of the effects of birthplace and migration to Sweden on subclinical atherosclerosis, Ann. Med. 34 (3) (2002) 162-170.

[17] D.H. O'Leary, J.F. Polak, R.A. Kronmal, T.A. Manolio, G.L. Burke, S.K. Wolfson Jr., Carotid-artery intima and media thickness as a risk factor for myocardial infarction and stroke in older adults. Cardiovascular Health Study Collaborative Research Group, N. Engl. J. Med. 340 (1) (1999) 14-22.

[18] T. Laatikainen, J. Critchley, E. Vartiainen, V. Salomaa, M. Ketonen, S. Capewell, Explaining the decline in coronary heart disease mortality in Finland between 1982 and 1997, Am. J. Epidemiol. 162 (8) (2005) 764-773.

[19] M.A. Kashef, G. Giugliano, Legacy effect of statins: 20-year follow up of the west of scotland coronary prevention study (WOSCOPS), Glob Cardiol Sci Pract [Internet] 2016 (4) (2017) e201635. Available from: http://www.ncbi.nlm.nih.gov/pubmed/ 28979904\%0Ahttp://www.pubmedcentral.nih.gov/articlerender.fcgi?artid= PMC5624184\%0Ahttps://globalcardiologyscienceandpractice.com/index.php/ gcsp/article/view/81.

[20] P. Kestilä, C.G. Magnussen, J.S. Viikari, M. Kähönen, N. Hutri-Kähönen, L. Taittonen, et al., Socioeconomic status, cardiovascular risk factors, and subclinical atherosclerosis in young adults: the cardiovascular risk in Young Finns Study, Arterioscler. Thromb. Vasc. Biol. 32 (3) (2012) 815-821.

[21] D.L. Kuh, C. Power, B. Rodgers, Secular trends in social class and sex differences in adult height, Int. J. Epidemiol. 20 (4) (1991) 1001-1009.

[22] T. Forsen, J. Eriksson, Q. Qiao, M. Tervahauta, A. Nissinen, J. Tuomilehto, Short stature and coronary heart disease: a 35-year follow-up of the Finnish cohorts of the Seven Countries Study, J. Intern. Med. 248 (4) (2000) 326-332.

[23] J.P. Kannam, D. Levy, M. Larson, P.W. Wilson, Short stature and risk for mortality and cardiovascular disease events. The Framingham Heart Study, Circulation 90 (5) (1994) 2241-2247.

[24] R.A. Kittles, M. Perola, L. Peltonen, A.W. Bergen, R.A. Aragon, M. Virkkunen, et al., Dual origins of Finns revealed by Y chromosome haplotype variation, Am. J. Hum. Genet. 62 (5) (1998) 1171-1179.

[25] T. Valkonen, Male mortality from ischaemic heart disease in Finland: relation to region of birth and region of residence, Eur. J. Popul. 3 (1) (1987) 61-83.

[26] P. Puska, E. Vartiainen, J. Tuomilehto, V. Salomaa, A. Nissinen, Changes in premature deaths in Finland: successful long-term prevention of cardiovascular diseases, Bull. World Health Organ. 76 (4) (1998) 419-425.

[27] Kansanterveyslaitos. Finravinto 2007 -tutkimus, (2008). 